\title{
Preoperative malnutrition with mild hypoalbuminemia associated with postoperative mortality and morbidity of colorectal cancer: a propensity score matching study
}

\author{
Wan-Hsiang $\mathrm{Hu}^{1,2,3}$, Samuel Eisenstein ${ }^{2}$, Lisa Parry ${ }^{2}$ and Sonia Ramamoorthy ${ }^{2,3^{*}}$
}

\begin{abstract}
Background: Malnutrition with hypoalbuminemia (albumin $<35 \mathrm{~g} / \mathrm{L}$ ) is an important factor in predicting risks associated with colorectal cancer surgery. However, there is limited data about the effects of mild hypoalbuminemia with small decreases in albumin on postoperative complications.

Methods: This is a retrospective study using the multi-institutional, nationally validated database of the American College of Surgeons-National Surgical Quality Improvement Program (ACS-NSQIP) to investigate mild hypoalbuminemia and its association with postoperative mortality and morbidity by using a propensity score matching method.

Results: In a group of 30,676 colorectal cancer patients who received surgery, 5230 had mild hypoalbuminemia $(<35$ and $>=30 \mathrm{~g} / \mathrm{L}$ ) and 21,310 had normal albumin levels (> = 35 g/L). Significant differences were noted in 21 clinical characteristics between the two groups. After $1: 2$ propensity score matching postoperative mortality was significantly associated with mild hypoalbuminemia $(\mathrm{OR}=1.74 ; p<0.001)$. There were significant associations between mild hypoalbuminemia and 11 postoperative morbidities including deep vein thrombosis, pulmonary embolism, superficial and deep surgical site infection, pneumonia, septic shock, ventilator $>48 \mathrm{~h}$, blood transfusion, return to operating room, stroke and re-intubation. Mild hypoalbuminemia was also associated with overall complication $(B=0.064, p<0.001)$ and length of total hospital stay $(B=2.236, p<0.001)$.

Conclusions: In colorectal cancer, this is the first propensity score matching study of malnutrition with mild hypoalbuminemia which demonstrates that a mild decrease in serum albumin contributes significantly to poor postoperative outcome.
\end{abstract}

Keywords: Mild hypoalbuminemia, Postoperative mortality and morbidity, Colorectal cancer, Propensity score matching

\section{Background}

Malnutrition is a significant risk factor in postoperative mortality, morbidities and length of hospital stay in hospitalized [1], surgical [2] and cancer patients [3]. Preoperative serum albumin serves as an excellent tool to assess

\footnotetext{
* Correspondence: sramamoorthy@mail.ucsd.edu

${ }^{2}$ Department of Surgery, University of California, San Diego Health System, La Jolla, San Diego, CA, USA

${ }^{3}$ Department of Surgery and Rebecca and John Moores Cancer Center, University of California San Diego, 3855 Health Sciences Drive, La Jolla, San Diego, CA 92093, USA

Full list of author information is available at the end of the article
}

malnutrition and to predict patient outcomes and survival [4-10]. Detection of hypoalbuminemia and appropriate intervention could decrease the complication rates [11] when associated with malnutrition.

In the United States, colorectal cancer is the third most common cancer [12] and it is the most common cancer in Taiwan [13]. Our previous study and other studies in the literature showed that malnutrition with hypoalbuminemia $(<35 \mathrm{~g} / \mathrm{L})$ is a predominant problem in colorectal cancer and is associated with poor postoperative outcomes [1416]. Serum albumin is a negative acute-phase protein with

(C) The Author(s). 2019 Open Access This article is distributed under the terms of the Creative Commons Attribution 4.0 International License (http://creativecommons.org/licenses/by/4.0/), which permits unrestricted use, distribution, and 
reduced expression and increased losses during inflammation processes [17] and in underweight people. Therefore hypoalbminemia is an indicator for malnutrition in acute and chronically ill patients. However, some studies concluded that hypoalbuminemia only becomes clinically significant at levels $<25 \mathrm{~g} / \mathrm{L}[18,19]$, and that albumin replacement is only covered by health insurance in Taiwan for patients with serum albumin levels $<30 \mathrm{~g} / \mathrm{L}$ and who exhibit associated comorbidities. Subgroup analyses of the association between a mild decrease of serum albumin $(<$ 35 and $>=30 \mathrm{~g} / \mathrm{L}$ ) and postoperative complications is rare and generally focused on procedures [20]. We wanted to study the effect of mild hypoalbuminemia on the postoperative outcomes in colorectal cancer patients.

The American College of Surgeons-National Surgical Quality Improvement Program (ACS-NSQIP) database records the preoperative comorbidities and postoperative complications of many kinds of operations from more than five hundred medical hospitals in the United States and Canada [21]. Propensity score matching provides a method to minimize bias from observational treatment cohorts and seeks to approximate the characteristics of a randomized clinical trial [22]. The purpose of this study was to apply propensity score matching to this robust database to compare the postoperative outcomes in colorectal cancer patients with mild hypoalbuminemia to those with normal serum albumin.

\section{Methods}

\section{Patient selection}

Data of the ACS-NSQIP from 2009 to 2013 was utilized to identify colorectal cancer patients using ICD-9 (International Classification of Disease, Ninth Revision) diagnosis codes (Additional file 1). Colorectal cancer patients undergoing related operations were selected by the Current Procedural Terminology (CPT) codes (Additional file 1) in: principle operative procedure; other procedure; or concurrent procedure records.

\section{Postoperative outcomes}

The primary outcomes studied were 30-day mortality, all morbidities, overall complication and length of total hospital stay. The postoperative morbidities included: surgical site infection (superficial, deep and organic); wound disruption; urinary tract infection; pneumonia; re-intubation; ventilator $>48 \mathrm{~h}$; pulmonary embolism; deep vein thrombosis; progressive renal insufficiency; acute renal failure; stroke; myocardial infarction; cardiopulmonary resuscitation; blood transfusion; sepsis; septic shock; and return to operating room. Mortality and morbidities were graded and weighted using the Accordion Severity Grading System [23, 24]. The overall complication score was calculated as the sum of the weighted scores in each patient.

\section{Statistical analysis}

For our analyses, "control" was defined by a normal serum albumin levels ( $>=35 \mathrm{~g} / \mathrm{L})$, and "case" was defined by mild hypoalbuminemia $(<35$ and $>=30 \mathrm{~g} / \mathrm{L})$ as measured by laboratory data collected within 2 weeks before surgery. Individual propensity scores were calculated by logistic regression method based on 21 clinical associated factors including age, gender, body mass index, smoking, emergent operation and other comorbidities. A 1:2 ratio propensity score matching study group was created using the Greedy method with a 0.2 caliper width using NCSS 10 software (NCSS Statistical Software, Kaysville, UT, USA) [25]. A chi-square test was used for univariate association. Binary logistic regression method was used to analyze the association between mild hypoalbuminemia and postoperative mortality and morbidity. The association among length of total hospital stay, overall morbidity and mild hypoalbuminemia was analyzed with regression analysis. Tests were two-tailed and statistical significance was defined at $p<0.05$. All statistical analyses were performed on SPSS for Windows version 22.

\section{Results}

From the database of the ACS-NSQIP during the years 2009 to 2013, a total of 30,676 colorectal cancer patients who received associated surgery were identified. We selected 5230 (17\%) with mild hypoalbuminemia (<35 and > $=30 \mathrm{~g} / \mathrm{L}$ ) and $21,310(70 \%)$ with normal serum albumin levels $(>=35 \mathrm{~g} / \mathrm{L})$ for further study. Significant differences with respect to 21 clinical characteristics were demonstrated between the two groups (Table 1). The patients with mild hypoalbuminemia were older, more likely to be thin, female, used tobacco and steroids more frequently, had more comorbidities, and higher grades of American Society of Anesthesiologists and wound classification. After 1:2 ratio propensity score matching, 4305 patients with mild hypoalbuminemia and 8610 normal patients were retained for comparison. No significant differences in previously associated covariates were noted between the two groups (Table 1).

Table 2 shows the difference of rates of postoperative outcomes between normal and mild hypoalbuminemia patients before matching. Mortality and all morbidities, except organic surgical site infection, were significantly associated with mild hypoalbuminemia. After matching, the patients with mild hypoalbuminemia still had significantly higher in-hospital mortality rates compared with those with normal albumin levels ( $2.3 \%$ vs. $1.3 \%$; OR $=1.74 ; p<0.001$ ) (Table 3). Low serum albumin had significant association with deep vein thrombosis $(\mathrm{OR}=1.99 ; p<0.001)$ and pulmonary embolism $(\mathrm{OR}=1.55 ; p=0.011)$. Problems related with infection including superficial surgical site infection, deep surgical site infection, pneumonia and septic shock occurred in patients with mild hypoalbuminemia. The 
Table 1 Selected Cohort Characteristics Before and After Propensity Score-Matching

\begin{tabular}{|c|c|c|c|c|c|c|}
\hline \multirow[t]{3}{*}{ Variables } & \multicolumn{3}{|l|}{ Full Cohort } & \multicolumn{3}{|l|}{ Matched Cohort (1:2) } \\
\hline & \multicolumn{2}{|l|}{ Albumin (g/dl) } & \multirow[t]{2}{*}{$P$ value } & \multicolumn{2}{|l|}{ Albumin $(\mathrm{g} / \mathrm{dl})$} & \multirow{2}{*}{$\begin{array}{l}P \\
\text { value }\end{array}$} \\
\hline & $<3.5$ and $>=3.0(n=5230)$ & $>=3.5(n=21,310)$ & & $<3.5$ and $>=3.0(n=4305)$ & $>=3.5(n=8610)$ & \\
\hline Age, mean (SD), y & $70.2(13.7)$ & $65.2(13.6)$ & $<0.001$ & $68.9(13.8)$ & $69.3(13.1)$ & 0.075 \\
\hline BMl, mean (SD) & $27.6(7.2)$ & $28.2(6.5)$ & $<0.001$ & $28(7.2)$ & $27.9(6.3)$ & 0.441 \\
\hline Gender, male, n(\%) & $2527(48.3)$ & $11,370(53.4)$ & $<0.001$ & $2140(49.7)$ & $4290(49.8)$ & 0.901 \\
\hline Smoking, n(\%) & 834(15.9) & $3125(14.7)$ & 0.02 & $677(15.7)$ & 1327(15.4) & 0.643 \\
\hline Ventilator, $\mathrm{n}(\%)$ & $6(0.1)$ & $12(0.05)$ & 0.146 & $4(0.09)$ & $3(0.03)$ & 0.181 \\
\hline COPD, n(\%) & $469(9)$ & $1061(5)$ & $<0.001$ & $325(7.5)$ & $607(7)$ & 0.301 \\
\hline Ascites, $n(\%)$ & $108(2.1)$ & $128(0.6)$ & $<0.001$ & $43(1)$ & $60(0.7)$ & 0.069 \\
\hline CHF, n(\%) & $137(2.6)$ & $161(0.8)$ & $<0.001$ & $42(1)$ & $74(0.9)$ & 0.51 \\
\hline Hypertension, n(\%) & $3104(59.3)$ & $11,492(53.9)$ & $<0.001$ & $2517(58.5)$ & $5072(58.9)$ & 0.631 \\
\hline Renal failure, n(\%) & $13(0.2)$ & $27(0.1)$ & 0.042 & $4(0.1)$ & $15(0.2)$ & 0.256 \\
\hline Dialysis, n(\%) & $47(0.9)$ & $80(0.4)$ & $<0.001$ & $21(0.5)$ & $48(0.6)$ & 0.609 \\
\hline$D C, n(\%)$ & $770(14.7)$ & 1977(9.3) & $<0.001$ & $539(12.5)$ & $1048(12.2)$ & 0.57 \\
\hline Steroid, n(\%) & $185(3.5)$ & $541(2.5)$ & $<0.001$ & $140(3.3)$ & 259(3) & 0.45 \\
\hline Emergency, n(\%) & $503(9.6)$ & $834(3.9)$ & $<0.001$ & $242(5.6)$ & $429(5)$ & 0.123 \\
\hline BWL, n(\%) & $606(11.6)$ & $1007(4.7)$ & $<0.001$ & $315(7.3)$ & $574(6.7)$ & 0.169 \\
\hline Diabetes mellitus, n(\%) & & & $<0.001$ & & & 0.679 \\
\hline No & 4083(78.1) & $17,604(82.6)$ & & $3415(79.3)$ & $6816(79.1)$ & \\
\hline Oral & 723(13.8) & $2702(12.7)$ & & $607(14.1)$ & 1194(13.9) & \\
\hline Insulin & $424(8.1)$ & $1004(4.7)$ & & $283(6.6)$ & $600(7)$ & \\
\hline Dyspnea & & & $<0.001$ & & & 0.590 \\
\hline No & $4443(85)$ & $19,340(90.8)$ & & $3753(87.2)$ & $7546(87.7)$ & \\
\hline Exertion & $696(13.3)$ & 1858(8.7) & & $515(12)$ & 1002(11.6) & \\
\hline Rest & $91(1.7)$ & $112(0.5)$ & & $37(0.8)$ & $62(0.7)$ & \\
\hline Systemic sepsis & & & $<0.001$ & & & 0.156 \\
\hline No & 4798(91.7) & $20,775(97.5)$ & & $4148(96.4)$ & $8355(97)$ & \\
\hline SIRS & $303(5.8)$ & $386(1.8)$ & & $114(2.6)$ & $188(2.2)$ & \\
\hline Sepsis & $118(2.3)$ & $128(0.6)$ & & $39(0.9)$ & $57(0.7)$ & \\
\hline Septic shock & $11(0.2)$ & $21(0.1)$ & & $4(0.1)$ & 10(0.1) & \\
\hline Functional status ${ }^{\mathrm{a}}, \mathrm{n}(\%)$ & & & $<0.001$ & & & 0.883 \\
\hline Independent & $4781(91.4)$ & 20,749(97.4) & & $4154(96.5)$ & 8322(96.6) & \\
\hline Partially Dependent & $381(7.3)$ & $504(2.4)$ & & $140(3.2)$ & $266(3.1)$ & \\
\hline Totally Dependent & $68(1.3)$ & $57(0.3)$ & & $11(0.3)$ & $22(0.3)$ & \\
\hline ASA & & & $<0.001$ & & & 0.169 \\
\hline I & $42(0.8)$ & $519(2.4)$ & & $42(1)$ & $95(1.1)$ & \\
\hline$\|$ & $1256(24)$ & $8779(41.2)$ & & $1213(28.2)$ & $2273(26.4)$ & \\
\hline III & $3307(63.2)$ & $11,009(51.7)$ & & $2753(63.9)$ & $5634(65.44)$ & \\
\hline IV & $620(11.9)$ & $996(4.67)$ & & $295(6.85)$ & $607(7.05)$ & \\
\hline v & $5(0.1)$ & $7(0.03)$ & & $2(0.05)$ & $1(0.01)$ & \\
\hline Wound & & & $<0.001$ & & & 0.343 \\
\hline$\|$ & $4526(86.5)$ & $19,604(92)$ & & 3885(90.24) & 7805(90.6) & \\
\hline III & $375(7.2)$ & 1252(5.9) & & $285(6.62)$ & $574(6.7)$ & \\
\hline IV & $329(6.3)$ & $454(2.1)$ & & 135(3.14) & $231(2.7)$ & \\
\hline
\end{tabular}

$B M I$ body mass index, COPD chronic obstructive pulmonary disease, CHF Congestive heart failure, DC Disseminated cancer, BWL body weight loss, $A S A$ American Society of Anesthesiologists, Wound II clean/contamination, Wound III contamination, Wound IV dirty ${ }^{a}$ assistance from another person for any activities of daily living 
other significant postoperative outcomes included ventilator dependence more than $48 \mathrm{~h}$, blood transfusion, return to operating room, stroke and re-intubation. Higher incidence of other postoperative complications, like wound disruption, were noted in the mild hypoalbuminemia patients.

Regression analyses revealed that overall complication and length of total hospital stay were associated with mild hypoalbuminemia. After matching, both overall complication $(\mathrm{B}=0.064, p<0.001)$ and length of total hospital stay $(\mathrm{B}=2.236, p<0.001)$ were still greater in the mild hypoalbuminemia group than in the group with normal serum albumin levels (Table 4).

\section{Discussion}

Using the nationally validated ACS-NSQIP database, our multi-institutional study demonstrates the effects of mild hypoalbuminemia on postoperative outcomes of colorectal cancer patients. We matched mild hypoalbuminemia patients and patients with normal serum albumin levels using a propensity score matching method to decrease the biases associated with the selecting of two groups with significant differences in other clinical characteristics. After matching, postoperative mortality, overall complication and length of hospital stay were still associated with mild hypoalbuminemia.

The association between hypoalbuminemia and comorbidities has been discussed in the literature. Hospitalized patients with mild hypoalbuminemia (albumin 25-35 g/L) were older, lower body mass index, and more hypertension, congestive heart failure and chronic renal failure than those with normal albumin levels [9]. Severe hypoalbuminemia was noted in $4 \%$ of chronic obstructive pulmonary disease patient and was a strong risk factor for developing acute renal failure [26]. The rates of hypoalbuminemia ranged from 20 to $25 \%$ in chronic heart failure patients to $90 \%$ in weak, elderly patients suffering from acute heart failure [27]. In our study, mild hypoalbuminemia was not rare and was significantly associated with many comorbidities in colorectal cancer patients. Because there is more postoperative risk associated with even mild hypoalbuminemia, early identification of malnutrition in patients with multiple comorbidities is recommended.

In our retrospective study, randomization was not possible. However, strong associations between mild hypoalbuminemia and the patients' clinical characteristics were demonstrated. We used a propensity score

Table 2 The association of postoperative mortality and morbidity in patients grouped by albumin level before propensity score matching

\begin{tabular}{|c|c|c|c|c|}
\hline \multirow[t]{2}{*}{ Postop outcomes } & \multicolumn{2}{|l|}{ Albumin $(\mathrm{g} / \mathrm{dl})$} & \multirow[t]{2}{*}{ OR $(95 \% \mathrm{Cl})$} & \multirow[t]{2}{*}{$P$ value } \\
\hline & $<3.5$ and $>=3.0(n=5230)$ & $>=3.5(n=21,310)$ & & \\
\hline 30-day mortality & 196(3.7) & $248(1.2)$ & $3.31(2.74-4.00)$ & $<0.001$ \\
\hline Stroke & $40(0.8)$ & $55(0.3)$ & $2.98(1.98-4.48)$ & $<0.001$ \\
\hline DVT & $142(2.7)$ & 239(1.1) & $2.46(2.00-3.04)$ & $<0.001$ \\
\hline Ventilator $>48 \mathrm{~h}$ & 183(3.5) & $319(1.5)$ & $2.39(1.98-2.87)$ & $<0.001$ \\
\hline Septic shock & 159(3) & $280(1.3)$ & $2.36(1.93-2.87)$ & $<0.001$ \\
\hline Transfusion & 991(18.9) & 2009(9.4) & $2.25(2.07-2.44)$ & $<0.001$ \\
\hline Re-intubation & 177(3.4) & $365(1.7)$ & $2.01(1.68-2.41)$ & $<0.001$ \\
\hline Pneumonia & $211(4)$ & $457(2.1)$ & $1.92(1.63-2.27)$ & $<0.001$ \\
\hline PRI & $70(1.3)$ & $163(0.8)$ & $1.76(1.33-2.33)$ & $<0.001$ \\
\hline Deep SSI & $113(2.2)$ & $302(1.4)$ & $1.54(1.24-1.91)$ & $<0.001$ \\
\hline Sepsis & $245(4.7)$ & $715(3.4)$ & $1.42(1.22-1.64)$ & $<0.001$ \\
\hline UTI & $217(4.1)$ & $646(3)$ & $1.39(1.18-1.62)$ & $<0.001$ \\
\hline Return to OR & $353(6.7)$ & $1068(5)$ & $1.37(1.21-1.55)$ & $<0.001$ \\
\hline Superficial SSI & $430(8.2)$ & $1411(6.6)$ & $1.26(1.13-1.41)$ & $<0.001$ \\
\hline ARF & $49(0.9)$ & $116(0.5)$ & $1.73(1.24-2.42)$ & 0.001 \\
\hline PE & $71(1.4)$ & $180(0.8)$ & $1.62(1.23-2.13)$ & 0.001 \\
\hline CPR & $44(0.8)$ & $103(0.5)$ & $1.75(1.23-2.49)$ & 0.002 \\
\hline $\mathrm{Ml}$ & $63(1.2)$ & 163(0.8) & $1.58(1.18-2.12)$ & 0.002 \\
\hline Wound disruption & $85(1.6)$ & 259(1.2) & $1.34(1.05-1.72)$ & 0.019 \\
\hline Organ SSI & $216(4.1)$ & $869(4.1)$ & $1.01(0.87-1.18)$ & 0.865 \\
\hline
\end{tabular}

Values in parentheses are percentage

$D V T$ deep vein thrombosis, $P R I$ progressive renal insufficiency, $S S /$ surgical site infection, UTI urinary tract infection, $O R$ operating room, $A R F$ acute renal failure, $P E$ pulmonary embolism, CPR cardiopulmonary resuscitation, MI myocardial infarction 
Table 3 The association of postoperative mortality and morbidity in patients grouped by albumin level after propensity score matching

\begin{tabular}{|c|c|c|c|c|}
\hline \multirow[t]{2}{*}{ Postop outcomes } & \multicolumn{2}{|l|}{ Albumin (g/dl) } & \multirow[t]{2}{*}{ OR $(95 \% \mathrm{Cl})$} & \multirow[t]{2}{*}{$P$ value } \\
\hline & $<3.5$ and $>=3.0(n=4305)$ & $>=3.5(n=8610)$ & & \\
\hline 30-day mortality & $98(2.3)$ & $114(1.3)$ & $1.74(1.32-2.28)$ & $<0.001$ \\
\hline DVT & $109(2.5)$ & $111(1.3)$ & $1.99(1.52-2.60)$ & $<0.001$ \\
\hline Ventilator $>48 \mathrm{~h}$ & $113(2.6)$ & $145(1.7)$ & $1.57(1.23-2.02)$ & $<0.001$ \\
\hline Transfusion & $737(17.1)$ & $991(11.5)$ & $1.59(1.43-1.76)$ & $<0.001$ \\
\hline Return to $O R$ & $291(6.8)$ & $447(5.2)$ & $1.32(1.14-1.54)$ & $<0.001$ \\
\hline Superficial SSI & $367(8.5)$ & $599(7)$ & $1.25(1.09-1.42)$ & 0.001 \\
\hline Pneumonia & $151(3.5)$ & $214(2.5)$ & $1.43(1.15-1.76)$ & 0.001 \\
\hline Septic shock & $100(2.3)$ & 133(1.5) & $1.52(1.17-1.97)$ & 0.002 \\
\hline Deep SSI & $98(2.3)$ & $138(1.6)$ & $1.43(1.10-1.86)$ & 0.007 \\
\hline PE & $60(1.4)$ & $78(0.9)$ & $1.55(1.10-2.17)$ & 0.011 \\
\hline Stroke & $27(0.6)$ & $28(0.3)$ & $1.93(1.14-3.29)$ & 0.013 \\
\hline Re-intubation & $124(2.9)$ & 193(2.2) & $1.29(1.03-1.63)$ & 0.027 \\
\hline Sepsis & 189(4.4) & $320(3.7)$ & $1.19(0.99-1.43)$ & 0.064 \\
\hline UTI & $173(4)$ & $304(3.5)$ & $1.14(0.95-1.38)$ & 0.166 \\
\hline Wound disruption & $69(1.6)$ & $116(1.3)$ & $1.19(0.88-1.61)$ & 0.249 \\
\hline PRI & $47(1.1)$ & $76(0.9)$ & $1.24(0.86-1.79)$ & 0.249 \\
\hline ARF & $31(0.7)$ & $48(0.6)$ & $1.29(0.82-2.04)$ & 0.264 \\
\hline MI & $50(1.2)$ & $91(1.1)$ & $1.10(0.78-1.56)$ & 0.590 \\
\hline Organ SSI & $176(4.1)$ & $366(4.3)$ & $0.96(0.80-1.15)$ & 0.664 \\
\hline CPR & $26(0.6)$ & $51(0.6)$ & $1.02(0.64-1.64)$ & 0.936 \\
\hline
\end{tabular}

Values in parentheses are percentage

$D V T$ deep vein thrombosis, OR operating room, SSI surgical site infection, $P E$ pulmonary embolism, $P R I$ progressive renal insufficiency, $A R F$ acute renal failure, UTI urinary tract infection, CPR cardiopulmonary resuscitation, $M I$ myocardial infarction

matching method to reduce the bias in estimating the effect of mild hypoalbuminemia on postoperative outcomes, and the likelihood of confounding when analyzing the observational data [28]. After matching, a mild decrease in serum albumin level still had serious effects on postoperative outcomes including increased mortality, morbidities, overall complication and length of total hospital stay.
After matching, venous thromboembolism (VTE), including deep vein thrombosis $(\mathrm{OR}=1.99)$ and pulmonary embolism $(\mathrm{OR}=1.55)$ was associated with mild hypoalbuminemia in our study. Aaron et al. [29] demonstrated low serum albumin was a modest marker of an increased risk of venous thromboembolism after adjusting for age, sex, race, use of hormone replacement therapy, estimated GFR, history of cancer, and diabetes. The

Table 4 Regression analysis of overall complication and length of total hospital stay in patients grouped by albumin level before and after propensity score matching

\begin{tabular}{|c|c|c|c|c|c|}
\hline Post-operative outcomes & Albumin $(\mathrm{g} / \mathrm{dl})$ & Mean & B (coefficient) & 95\% C.I. & $P$ value \\
\hline \multirow[t]{2}{*}{ Overall Complication ${ }^{\mathrm{b}}$} & $<3.5$ and $>=3.0$ & 0.2821 & 0.121 & $0.107-0.135$ & $<0.001$ \\
\hline & $>=3.5$ & 0.1612 & 0 & 0 & \\
\hline \multirow[t]{2}{*}{ Length of total hospital stay ${ }^{b}$} & $<3.5$ and $>=3.0$ & 11.0069 & 3.453 & $3.201-3.705$ & $<0.001$ \\
\hline & $>=3.5$ & 7.5539 & 0 & 0 & \\
\hline \multirow[t]{2}{*}{ Overall Complication $^{\mathrm{a}}$} & $<3.5$ and $>=3.0$ & 0.2468 & 0.064 & $0.047-0.082$ & $<0.001$ \\
\hline & $>=3.5$ & 0.1826 & 0 & 0 & \\
\hline \multirow[t]{2}{*}{ Length of total hospital stay ${ }^{a}$} & $<3.5$ and $>=3.0$ & 10.4407 & 2.236 & $1.902-2.57$ & $<0.001$ \\
\hline & $>=3.5$ & 8.2045 & 0 & 0 & \\
\hline
\end{tabular}

\footnotetext{
${ }^{\mathrm{b}}$ before; ${ }^{\mathrm{a}}$ after
} 
adjusted hazard ratio for albumin below the fifth percentile was 1.28 and 1.8 in their two cohorts' data. Hypoalbuminemia (serum albumin level $<35 \mathrm{mg} / \mathrm{L}$ ) was reported to be associated with deep vein thrombosis (AOR 1.69) in colon and rectal surgery [30]. In cancer patients, a similar result was also noted [31]. The mechanism of association between hypoalbuminemia and VTE is poorly understood but may be due to hyperinflammatory or hypercoagulable states. Further studies of the mechanism are necessary, and closer monitoring for VTE in cancer patients with hypoalbuminemia is recommended.

A multi-institutional study showed preoperative hypoalbuminemia (serum albumin $<30 \mathrm{~g} / \mathrm{L}$ ) was an independent predictor for development of superficial and deep surgical site infection and prolonged hospital stay following gastrointestinal surgery [32]. The associations were also reported in other operative procedures [3335]. In our study, a mild decrease in serum albumin also had a significant effect on surgical site infection, pneumonia, septic shock and length of total hospital stay. Low serum albumin was an excellent assessment tool for malnutrition [14], which was associated with poor wound healing [36] and infection [37]. Albumin serves an immunomodulatory role [38], and impairment of macrophage activation and granuloma formation were noted in hypoalbuminemic mice [39]. Serum albumin is a negative acute-phase protein during inflammatory reaction by bacterial infection [40]. These factors may promote surgical site infection and pneumonia in hypoalbuminemia and in mild hypoalbuminemic colorectal cancer patients.

There are several limitations to our study. First, the database only records the events that happened during the 30-day postoperative period, so it may not correctly estimate the true rate of postoperative outcomes, some of which may have occurred after 30 days. Second, nutritional supplementation may have been given to mild hypoalbuminemia patients and the information was not recorded. This means that part of the patients with mild hypoalbuminemia might receive supplementation preand postoperatively and their outcome was supposedly improved. The data of patients being purely without nutrition supplementation would make the results, ie. the mild hypoalbuminemia associated with worse outcome more contrasting. In addition, some of the important postoperative complications associated with colorectal surgery, like anastomotic leakage and ileus were not included in the database. Finally, the database has no cancer-specific variables like stage and tumor size, which may interact with mild hypoalbuminemia in postoperative outcome evaluation. We excluded the patients who only received palliative surgery to minimize the effect of the advanced stage on postoperative complications.

\section{Conclusions}

In colorectal cancer patients, malnutrition with mild hypoalbuminemia is a common problem and associated with more comorbidities. After propensity score matching, a significant association with many postoperative complications was demonstrated. Randomized controlled trials are needed to evaluate if early identification and aggressive nutritional intervention in patients with even mild hypoalbuminemia would reduce the rate of postoperative complications and improve postoperative outcomes.

\section{Additional file}

Additional file 1: ICD-9 code and CPT code. (DOCX 50 kb)

\section{Abbreviations}

ACS-NSQIP: American College of Surgeons-National Surgical Quality Improvement Program; CPT: Current Procedural Terminology; ICD-9: International Classification of Disease, Ninth Revision

\section{Acknowledgements}

We thank Prof. Sheng-Nan Lu, Chih-Yun Lin, Shin-Yi Chien, and the Biostatistics Center, Kaohsiung Chang Gung Memorial Hospital for statistics work.

\section{Authors' contributions}

WHH was involved in interpretation of data, statistical analysis and drafting the manuscript. SE and LP participated in revising the manuscript for important intellectual content. SR was responsible for study design and final approval of the manuscript. All authors read and approved the final manuscript.

\section{Funding \\ There is no any funding for the research.}

Availability of data and materials

Not applicable.

\section{Ethics approval and consent to participate}

The data is de-identified and contains no patient information. The data is considered exempt from human subjects review.

Consent for publication

Our manuscript doesn't contain any individual person's data.

\section{Competing interests}

The authors declare that they have no competing interests.

\section{Author details}

${ }^{1}$ Department of Colorectal Surgery, Kaohsiung Chang Gung Memorial Hospital, Chang Gung University College of Medicine, Kaohsiung, Taiwan. 2Department of Surgery, University of California, San Diego Health System, La Jolla, San Diego, CA, USA. ${ }^{3}$ Department of Surgery and Rebecca and John Moores Cancer Center, University of California San Diego, 3855 Health Sciences Drive, La Jolla, San Diego, CA 92093, USA.

Received: 5 October 2018 Accepted: 11 June 2019

Published online: 28 June 2019

\section{References}

1. Correia MI, Waitzberg DL. The impact of malnutrition on morbidity, mortality, length of hospital stay and costs evaluated through a multivariate model analysis. Clin Nutr. 2003;22:235-9.

2. Leandro-Merhi VA, de Aquino JL, Sales Chagas JF. Nutrition status and risk factors associated with length of hospital stay for surgical patients. JPEN J Parenter Enteral Nutr. 2011;35:241-8. 
3. Gupta D, Vashi PG, Lammersfeld CA, Braun DP. Role of nutritional status in predicting the length of stay in cancer: a systematic review of the epidemiological literature. Ann Nutr Metab. 2011;59:96-106.

4. Gibbs J, Cull W, Henderson W, Daley J, Hur K, Khuri SF. Preoperative serum albumin level as a predictor of operative mortality and morbidity: results from the national VA surgical risk study. Arch Surg. 1999;134:36-42.

5. Lohsiriwat V, Lohsiriwat D, Boonnuch W, Chinswangwatanakul V, Akaraviputh T, Lert-Akayamanee N. Pre-operative hypoalbuminemia is a major risk factor for postoperative complications following rectal cancer surgery. World J Gastroenterol. 2008;14:1248-51.

6. Lai CC, You JF, Yeh CY, Chen JS, Tang R, Wang JY, Chin CC. Low preoperative serum albumin in colon cancer: a risk factor for poor outcome. Int J Color Dis. 2011;26:473-81.

7. Truong A, Hanna MH, Moghadamyeghaneh Z, Stamos MJ. Implications of preoperative hypoalbuminemia in colorectal surgery. World J Gastrointest Surg. 2016;8:353-62.

8. Hu WH, Chen HH, Lee KC, Liu L, Eisenstein S, Parry L, Cosman B, Ramamoorthy $S$. Assessment of the addition of hypoalbuminemia to ACSNSQIP surgical risk calculator in colorectal Cancer. Medicine (Baltimore). 2016;95:e2999

9. Akirov A, Masri-lraqi H, Atamna A, Shimon I. Low albumin levels are associated with mortality risk in hospitalized patients. Am J Med. 2017;130; 1465.e1411-9.

10. Ahn J, Sundaram V, Ayoub WS, Frenette C, Wong RJ. Hypoalbuminemia is associated with significantly higher liver transplant waitlist mortality and lower probability of receiving liver transplant. J Clin Gastroenterol. 2018; 52(10):913-17.

11. Vincent JL, Dubois MJ, Navickis RJ, Wilkes MM. Hypoalbuminemia in acute illness: is there a rationale for intervention? A meta-analysis of cohort studies and controlled trials. Ann Surg. 2003;237:319-34.

12. Siegel R, Ma J, Zou Z, Jemal A. Cancer statistics, 2014. CA Cancer J Clin. 2014;64:9-29.

13. Chiang CJ, Lo WC, Yang YW, You SL, Chen CJ, Lai MS. Incidence and survival of adult cancer patients in Taiwan, 2002-2012. J Formos Med Assoc. 2016;115:1076-88.

14. Hu WH, Cajas-Monson LC, Eisenstein S, Parry L, Cosman B, Ramamoorthy S. Preoperative malnutrition assessments as predictors of postoperative mortality and morbidity in colorectal cancer: an analysis of ACS-NSQIP. Nutr J. 2015;14:91.

15. Haskins IN, Baginsky M, Amdur RL, Agarwal S. Preoperative hypoalbuminemia is associated with worse outcomes in colon cancer patients. Clin Nutr. 2017;36:1333-8.

16. Hardt J, Pilz L, Magdeburg J, Kienle P, Post S, Magdeburg R. Preoperative hypoalbuminemia is an independent risk factor for increased high-grade morbidity after elective rectal cancer resection. Int J Color Dis. 2017;32:1439-46.

17. Correction. Acute-phase proteins and other systemic responses to inflammation. N Engl J Med. 1999;340:1376.

18. Gatta A, Verardo A, Bolognesi M. Hypoalbuminemia. Intern Emerg Med. 2012;7(Suppl 3):S193-9.

19. Moujaess E, Fakhoury M, Assi T, Elias H, El Karak F, Ghosn M, Kattan J. The therapeutic use of human albumin in cancer patients' management. Crit Rev Oncol Hematol. 2017;120:203-9.

20. Moghadamyeghaneh Z, Hwang G, Hanna MH, Phelan MJ, Carmichael JC, Mills SD, Pigazzi A, Dolich MO, Stamos MJ. Even modest hypoalbuminemia affects outcomes of colorectal surgery patients. Am J Surg. 2015;210:276-84

21. Bilimoria KY, Liu Y, Paruch JL, Zhou L, Kmiecik TE, Ko CY, Cohen ME. Development and evaluation of the universal ACS NSQIP surgical risk calculator: a decision aid and informed consent tool for patients and surgeons. J Am Coll Surg. 2013;217:833-842 e831-833.

22. McMillan MT, Zureikat AH, Hogg ME, Kowalsky SJ, Zeh HJ, Sprys MH, Vollmer CM Jr. A propensity score-matched analysis of robotic vs open Pancreatoduodenectomy on incidence of pancreatic fistula. JAMA Surg. 2017:152:327-35

23. Strasberg SM, Linehan DC, Hawkins WG. The accordion severity grading system of surgical complications. Ann Surg. 2009;250:177-86.

24. Vollmer CM Jr, Lewis RS, Hall BL, Allendorf JD, Beane JD, Behrman SW, Callery MP, Christein JD, Drebin JA, Epelboym I, et al. Establishing a quantitative benchmark for morbidity in pancreatoduodenectomy using ACS-NSQIP, the accordion severity grading system, and the postoperative morbidity index. Ann Surg. 2015;261:527-36.
25. Kuo SCH, Kuo PJ, Rau CS, Chen YC, Hsieh HY, Hsieh CH. The protective effect of helmet use in motorcycle and bicycle accidents: a propensity score-matched study based on a trauma registry system. BMC Public Health. 2017:17:639.

26. Chen CW, Chen YY, Lu CL, Chen SC, Chen YJ, Lin MS, Chen W. Severe hypoalbuminemia is a strong independent risk factor for acute respiratory failure in COPD: a nationwide cohort study. Int J Chron Obstruct Pulmon Dis. 2015;10:1147-54.

27. Arques S. Human serum albumin in cardiovascular diseases. Eur J Intern Med. 2018;52:8-12.

28. Haukoos JS, Lewis RJ. The propensity score. JAMA. 2015:314:1637-8.

29. Folsom AR, Lutsey PL, Heckbert SR, Cushman M. Serum albumin and risk of venous thromboembolism. Thromb Haemost. 2010;104:100-4.

30. Moghadamyeghaneh Z, Hanna MH, Carmichael JC, Nguyen NT, Stamos MJ. A nationwide analysis of postoperative deep vein thrombosis and pulmonary embolism in colon and rectal surgery. J Gastrointest Surg. 2014; 18:2169-77.

31. Konigsbrugge O, Posch F, Riedl J, Reitter EM, Zielinski C, Pabinger I, Ay $C$. Association between decreased serum albumin with risk of venous thromboembolism and mortality in Cancer patients. Oncologist. 2016;21:252-7.

32. Hennessey DB, Burke JP, Ni-Dhonochu T, Shields C, Winter DC, Mealy K. Preoperative hypoalbuminemia is an independent risk factor for the development of surgical site infection following gastrointestinal surgery: a multi-institutional study. Ann Surg. 2010;252:325-9.

33. Lee Il, Kwon M, Roh JL, Choi JW, Choi SH, Nam SY, Kim SY, Postoperative hypoalbuminemia as a risk factor for surgical site infection after oral cancer surgery. Oral Dis. 2015;21:178-84.

34. Bohl DD, Shen MR, Kayupov E, Della Valle CJ. Hypoalbuminemia independently predicts surgical site infection, pneumonia, length of stay, and readmission after Total joint arthroplasty. J Arthroplast. 2016;31:15-21.

35. Sullivan SA, Van Le L, Liberty AL, Soper JT, Barber EL. Association between hypoalbuminemia and surgical site infection in vulvar cancers. Gynecol Oncol. 2016;142:435-9

36. Ward MW, Danzi M, Lewin MR, Rennie MJ, Clark CG. The effects of subclinical malnutrition and refeeding on the healing of experimental colonic anastomoses. Br J Surg. 1982:69:308-10.

37. Schaible UE, Kaufmann SH. Malnutrition and infection: complex mechanisms and global impacts. PLoS Med. 2007:4:e115.

38. Garcia-Martinez R, Andreola F, Mehta G, Poulton K, Oria M, Jover M, Soeda J, Macnaughtan J, De Chiara F, Habtesion A, et al. Immunomodulatory and antioxidant function of albumin stabilises the endothelium and improves survival in a rodent model of chronic liver failure. J Hepatol. 2015:62:799-806.

39. Reynolds JV, Redmond HP, Ueno N, Steigman C, Ziegler MM, Daly JM, Johnston RB Jr. Impairment of macrophage activation and granuloma formation by protein deprivation in mice. Cell Immunol. 1992;139:493-504.

40. Charlie-Silva I, Klein A, Gomes JMM, Prado EJR, Moraes AC, Eto SF, Fernandes DC, Fagliari JJ, Junior JDC, Lima C, et al. Acute-phase proteins during inflammatory reaction by bacterial infection: fish-model. Sci Rep. 2019;9:4776.

\section{Publisher's Note}

Springer Nature remains neutral with regard to jurisdictional claims in published maps and institutional affiliations.

Ready to submit your research? Choose BMC and benefit from:

- fast, convenient online submission

- thorough peer review by experienced researchers in your field

- rapid publication on acceptance

- support for research data, including large and complex data types

- gold Open Access which fosters wider collaboration and increased citations

- maximum visibility for your research: over $100 \mathrm{M}$ website views per year

At $\mathrm{BMC}$, research is always in progress.

Learn more biomedcentral.com/submissions 